This item was submitted to Loughborough's Research Repository by the author.

Items in Figshare are protected by copyright, with all rights reserved, unless otherwise indicated.

\title{
Exploring the roles of external facilitators in IT-driven open strategizing
}

PLEASE CITE THE PUBLISHED VERSION

http://dx.doi.org/10.1145/2957792.2957807

PUBLISHER

ACM $\odot$ the authors

VERSION

AM (Accepted Manuscript)

LICENCE

CC BY-NC-ND 4.0

REPOSITORY RECORD

Morton, Josh, Alexander D. Wilson, and Louise Cooke. 2019. "Exploring the Roles of External Facilitators in Itdriven Open Strategizing". figshare. https://hdl.handle.net/2134/22069. 


\section{Exploring the roles of external facilitators in IT-driven open strategizing}

\author{
Josh Morton \\ Loughborough University \\ School of Business and Economics \\ Epinal Way, Loughborough, \\ Leicestershire, LE113TU \\ J.Morton@lboro.ac.uk
}

\author{
Alex Wilson \\ Loughborough University \\ School of Business and Economics \\ Epinal Way, Loughborough, \\ Leicestershire, LE11 3TU \\ A.Wilson8@lboro.ac.uk
}

\author{
Louise Cooke \\ Loughborough University \\ School of Business and Economics \\ Epinal Way, Loughborough, \\ Leicestershire, LE113TU \\ L.Cooke@lboro.ac.uk
}

\begin{abstract}
This paper examines the different roles external facilitators have in information technology driven open strategizing. Using a strategyas-practice lens and drawing on two empirical cases of open strategy in organizations, our paper highlights four emerging roles of external facilitators which we call; structuring, promoting, moderating and analyzing. In concluding the paper we call for further research relating to external facilitators and open strategy.
\end{abstract}

\section{Keywords}

Open Strategy; Open Strategizing; Information Technology; Strategy-as-Practice; Facilitators; Strategy Consultants; Twitter; InnovationJam

\section{INTRODUCTION}

The past two decades has seen an increasing interest in information technology (IT) driven open phenomena. Prominent examples of 'openness', which have received particular attention from management scholars, include open innovation [3], crowdsourcing [8] and open collaboration [15]. Openness, in this IT-oriented context, refers broadly to accessibility of knowledge, transparency of action and the permeability of organizational structures. In particular, these open approaches emphasize the value of interacting more broadly with both internal and external actors, seeking input, and exercising increased notions of inclusion and transparency [19]. IT such as social media and collaborative software, in particular, are revolutionizing these inclusive and transparent communication processes within organizations, and altering the dynamic of social interaction [1]. This openness paradigm has more recently been applied to extending strategic practice. Despite strategy traditionally being the role of the corporate elite, organizations are increasingly embracing IT as a means of being more inclusive and transparent in their strategy making [19]. "Open strategy", a term first used in this context by Chesbrough and Appleyard [4], has been widely used to represent this mode of inclusive and transparent strategic practice. Scholars have started to recognize the shift in open strategy in bringing together internal and external stakeholders, particularly through inclusion in strategic idea generation and knowledge sharing (e.g. [16], [11]).

SAMPLE: Permission to make digital or hard copies of all or part of this work for personal or classroom use is granted without fee provided that copies are not made or distributed for profit or commercial advantage and that copies bear this notice and the full citation on the first page. To copy otherwise, or republish, to post on servers or to redistribute to lists, requires prior specific permission and/or a fee.

Conference'10, Month 1-2, 2010, City, State, Country.

Copyright 2010 ACM 1-58113-000-0/00/0010 ...\$15.00.
Strategy literature has also long discussed the role of external consultants or facilitators in the strategic practices of an organization (e.g. [14]). This revives debate around the role that external agents have in the strategy process, particularly how collaborating with external facilitators can be used as a way of facilitating the generation of higher-level discourse, through separation of strategic practice from mainstream organizational structures [7]. Within strategic practice, Hendry and Seidl [7] refer to the role of external facilitators in "strategic episodes" as "outsiders", who "bring with them new discursive structures and, through their presence and involvement, disrupt and replace the organizational structures of hierarchy and communication". However, scholars have only vaguely mentioned external facilitators in relation to the open strategy phenomenon, most notably the role of consultants in creating spaces for episodes of strategizing (e.g. strategy 'Jams' [19], [12], and strategy workshops [6]). Within the emerging field of open strategy, the role of external facilitators warrants closer inspection, exploring the potential significance of these individuals or groups. In particular, there has been scarce focus on the actual mechanisms exhibited by external facilitators, and this paper aims to further examine the specific roles of these 'outsiders' in IT-driven, open strategizing practices.

In this paper we draw on two contrasting empirical episodes of strategizing, from which we highlight the roles being conducted by external facilitators in the practice of open strategy. We propose the following research question: "What roles do external facilitators have in IT-driven open strategizing?'. Our conclusion briefly considers some avenues for further research as a result of the findings presented here.

\section{BACKGROUND AND LITERATURE REVIEW}

\subsection{Theoretical Background}

The approaches connected with the strategy-as-practice (SaP) approach (e.g. [18]) conceptualize strategy as "a situated, socially accomplished activity constructed through the interactions of multiple actors" [9]. Thus, strategy is not understood as a fixed property of an organization (something they have), it is something organizational actors do. The $\mathrm{SaP}$ approach focusses on the sociological aspects of strategy, arguing that the actual practices of strategy have been long overlooked in favor of a macro, organization-level focus. Indeed, the S-as-P approach switches the focus to the micro level analysis of the strategy phenomenon. Models of the SaP framework (e.g. [18]) emphasize the importance of narrowing the focus to the study of praxis, practices and practitioners. These three individual elements help us to explain the phenomenon of open strategizing activity; that is the people strategizing or 'doing' strategy (strategy practitioners), the strategy tools and practices used to do strategy (practices) and the actual 
"stream of activity in which strategy is accomplished over time" (praxis) [10]. In simplified terms, the central interest of $\mathrm{SaP}$ is to focus on explaining who strategists are, what they do, and why and how that is influential for strategic practice [9]. Thus, in the context of this paper, this raises the central question regarding the roles played by external actors in open strategy, particularly how external actors or groups aid the facilitation of IT-driven open strategizing and what particular roles they have.

\subsection{Literature Review}

This review highlights cases where external facilitators are present in open strategy literature, including in peer-reviewed academic literature, and non-peer reviewed literature such as practitioner reports, books and consultancy blogs. Our search criteria for this review deemed a case to be relevant when it related specifically to the strategy process (rather than innovation, for example), and demonstrated an opening-up of the strategy process to a wider range of actors, either through greater inclusion (actively inviting actors to participate in strategy) or transparency (communicating strategy to a wider range of actors) [19]. We avoided including any cases which were published by organizations as a means of promotional material, to minimize obvious bias or rhetorical treatment of openness. The search was conducted using keywordcentered reviews and concept-centric approaches [17]. A range of search terms were used based on keywords primarily from a combination of different terms to represent strategy and terms to represent openness; e.g. 'open', 'openness', 'strategy', 'strategizing', 'co-creation', 'collaboration'. Our aim was to understand more about open strategy activity in organizations, with a particular focus on the praxis, practices and practitioners involved in open strategizing. These searches identified 19 cases of open strategy and a near ubiquitous use of IT platforms [1], such as social media and social collaborative software (eighteen made use of an IT platform). Further, we found that open strategy frequently involves external actors or groups (such as partners or consultants) as an active part of the open strategy process. Half of the cases identified made clear reference to involving external facilitators as part of the open strategy process. Specific examples include Greenpeace's use of visual storytelling firm ImageThink to facilitate strategic conversations with employees (e.g. [5]), the Vienna Tourist Board's collaboration with external consultancy group inno-focus to create a bespoke ideation platform for their five year tourism strategy [2] and Wikimedia's work with consultancy firm Bridgespan Group, to create an online 'strategy wiki', facilitating the development of a five year strategy with the Wikimedia community [13]. For the purposes of space in this paper, and in order to focus detail on the analysis of our empirical work, we do not present all of these case examples here, however interested scholars and practitioners are welcome to request these from the lead author.

\section{METHODOLOGY}

The empirical focus of this paper draws on IT-driven strategizing episodes from two case studies, selected for their recent engagement with open strategy initiatives. The first case focuses on an IBM hosted InnovationJam (an InnovationJam, sometimes called 'Jamming' is an IBM process to represent their hosting of massively parallel conferences online) for a UK based public defense organization (which we call 'Defense-Co'). The second case explores how a UK professional body for library and information professionals (which we call 'InfoLib') utilized Twitter for an open strategic discussion, with facilitation by UKLC, an external interest group. Together, the case studies used qualitative data collection techniques, primarily in the form of 36 in-depth semi-structured interviews with those involved in both the planning and participation of open strategy, and non-participant observation of open strategic practices. Documentation data was also significant, and included data from social IT platforms actively utilized for open strategizing, feedback questionnaires, promotional material and outputs such as summative reports and strategic documents.

In analyzing these two empirical cases, we focus on the role of external facilitators in the IT-driven open strategy process. The data were analyzed using the $\mathrm{SaP}$ framework as an empirical lens, following the notion of practice as empirical phenomenon. In doing so we highlight the different external practitioners and begin to unpack their bundled practices through the initiation, conduct and aftermath of diverse forms of open strategy praxis.

\section{OVERVIEW OF OPEN STRATEGY CASE STUDIES}

\subsection{Case 1: Defense-Co InnovationJam}

In May 2015 IBM facilitated an InnovationJam for Defense-Co, a UK based public defense organization. The 'Jam' was hosted on a web collaboration platform, lasted two days, involved 67 participants and generated 90 strategic ideas with a combined total of 287 discussion posts. It was focused around three strategic topics. The InnovationJam was structured as a means of engaging Defense-Co employees and as part of a larger organizational transformation project driven by a new Chief Information Officer (CIO). The event was formally arranged and structured by IBM, who spent around nine months planning the InnovationJam, which included building the online environment (on IBM connections, a social collaborative platform), helping to define the Jam format and questions, registering participants on the platform and conducting a 'trial Jam'. Additionally, IBM designed and distributed a poster to promote the InnovationJam. This was primarily used at 'roadshow' events by Defense-Co.

During the two day event IBM acted as moderators, ensuring that conversations were developing, whilst guiding the structure of the event. The first day focused on idea generation, whilst the second day was focused on refining and prioritizing ideas. As noted in the IBM planning documents for the InnovationJam, the aim of day one was to "facilitate, encourage idea generation, the more the better" whilst day two was concerned with "refining ideas by online $Q \& A$ and facilitation. Prioritizing ideas by voting". The event was considered successful by both Defense-Co and IBM, although experienced lower participation levels than anticipated. IBM posted a survey on IBM connections after the Jam and encouraged participants to offer their feedback, including what they thought of the event, how they thought it might be improved, and whether they thought Defense-Co should repeat similar Jams in the future. IBM also provided Defense-Co with an in-depth report of the event, which included analysis graphs for participation and ideas generated, and lessons learnt from the Jam (for example one lesson was to improve mobile access to IBM connections for future Jams). Based on the process and evidence produced in the output regarding engagement with employees, Defense-Co are working on implementing three of the most popular ideas generated from the InnovationJam, and plan to explore future uses of Jamming in other areas of their business.

\subsection{Case 2: InfoLib Strategy Twitter Discussion}

From September to December 2015 InfoLib, a UK based professional body, which represents library and information 
professionals, led an open strategy consultation. The main consultation ran over a period of approximately three months, and sought engagement and feedback from all of its members, upwards of 13000 , and any other interested parties such as library and information interest groups and former members. The consultation offered an open call for interested actors to express their views about what InfoLib should focus upon in the formulation of their upcoming four year strategy. The consultation has resulted in the publication of a summative report of the initiative, and draft and final strategy action plans. The InfoLib CEO explained that the consultation was designed as "an exercise in open strategy", seeking to engage the widest possible group of stakeholders, both members and non-members, in all four nations across the UK in the process of defining their future plans. The CEO also explained that the process was an opportunity to engage with the organization's decreasing membership, and as a way to take sole responsibility away from the senior management team and board. In total, the tools used captured the opinions of over 1000 stakeholders; primarily active members. The main tools used were online questionnaires, face-to-face consultation events, and Twitter, which offered members the opportunity to express views under a designated 'hashtag'.

Additionally, a Twitter discussion event was held, taking place over a period of two hours. This event was hosted by UKLC, an external library professional's interest group, and was focused around twelve questions about InfoLib's next strategic plan. Six of these were structured by InfoLib and six were structured by members. UKLC opened an agenda on their website for members to submit potential questions. The website and social media channels were also used by UKLC to advertise the event. The Twitter discussion generated over 1000 tweets with participation from members of InfoLib, non-members, former members and other interested individuals. Over the course of the two hour event, UKLC posted updates and informed participants when the conversation was focusing on the next question. The event was deemed a success in terms of participation and engagement, and allowed an open conversation between members and the InfoLib CEO. Shortly after the event had concluded UKLC produced an analysis of the event in the form of a Twitter 'Storify', which ordered the tweets chronologically so interested parties who missed the event could study the output at a later stage in a structured format. This output was also deemed a valuable tool for InfoLib to use in their ongoing strategy initiative, and was used to analyze member opinions as part of the wider consultation process.

\section{ROLES OF EXTERNAL FACILITATORS IN OPEN STRATEGIZING}

The discussion of the two case studies leads to formal identification of the roles of external facilitators in these IT-driven initiatives. In analyzing these cases, we have identified four main roles which are exhibited by external facilitators. These are summarized in the following sub-sections. We label these roles as; 'structuring', 'promoting', 'moderating' and 'analyzing'.

\subsection{Structuring}

The structuring of both open strategy activities was primarily led by the external facilitators. IBM selected a suitable technology platform for the InnovationJam, structured the online environment by creating specific ideation forums for each of the three strategic topics being discussed, and registered participants onto the platform in advance with custom participant profiles which included name, role and optional features such as profile picture.
"IBM really facilitated the whole process, and were involved right the way through...it was about learning about the client and testing new ideas with them"- IBM Consultant

UKLC use Twitter for all of their events, and structured the strategy discussion based on their usual format. This included naming the event, setting a date and time, and hosting the event under their custom Twitter hashtag. The organization also created an event agenda for the discussion, which was open for participants to suggest questions which would be included as part of the structured discussion with InfoLib's CEO.

"(UKLC is) a monthly discussion group that takes place on Twitter once a month, usually from 6.30 to $8.30 \mathrm{pm}$. Our topics for discussion were proposed by participants and added to an agenda circulated in an open document format via the website and Twitter the week preceding the talk"'- UKLC Volunteer

\subsection{Promoting}

The external facilitators also had a significant role in the promotion of the open strategy activities. IBM encouraged the organization to actively promote the InnovationJam, and created a poster for senior Defense-Co managers to use at a number of roadshows. This poster was primarily used to explain the concept of an InnovationJam, and why participation would be valued.

"(The aim of the InnovationJam was to ) have a focused discussion around change and strategy, transformation, and things that the employees want"'- IBM Consultant

UKLC promoted the event using their webpages, creating a custom news article promoting the event with details including date, time and how to participate. As mentioned, this also included a custom agenda for the event. UKLC also actively promoted the event via their Twitter account.

"To go along with the event, we had an article from the CEO of InfoLib, telling us more about the challenges ahead and what they hope to achieve from their current consultation project for developing their strategic plan"'- UKLC Volunteer

\subsection{Moderating}

Both IBM and UKLC were actively involved in the live conduct of the open strategy initiatives. IBM acted as InnovationJam moderators, with the role of joining discussions to help develop conversations and ideas, whilst also moving the Jam along a timeline from idea generation, to idea voting and then refinement and reflection.

"Initially, we wanted them (Defense-Co) to help with the moderation, but as it happened we ended up doing the moderation. So basically it was a two day Jam and I personally ended up moderating a lot of it"'- IBM Consultant

UKLC had a similar role, actively posting during the event, particularly to moderate and move the conversation through each of the twelve pre-defined questions, whilst keeping time to ensure each question was allowed sufficient coverage. They also moderated and allowed for more popular questions to be discussed for longer periods, whilst progressing the conversation along from topics which were generating less discussion and engagement.

"Questions from the agenda will be posed during the discussion and moderated by a member of the team. Responses from different respondents are grouped together by including the hashtag within the replies"'- UKLC Volunteer 


\subsection{Analyzing}

The two external facilitators also produced output from the open strategy initiatives. IBM created in-depth analysis documents and designed and analyzed participant questionnaires as part of their consultancy service relating to the InnovationJam. This analysis included data relating to participation numbers, ideas generated and lessons learnt.

"We did post-Jam findings and documented these. A lot of this was based on doing quite a comprehensive questionnaire at the end of the Jam, which a good number of people filled in"- IBM Consultant

UKLC produced a less in-depth analysis, in the form of a Twitter 'Storify', a means of social media storytelling. As part of the Storify process, UKLC ordered tweets from the event chronologically by question, so that InfoLib had a 'take home' from the event to use for their wider strategy consultation project.

"The conversations are summarized and posted as blog entries on the website so they can be referred to at a later date. We found Storify to be a more efficient way to showcase a Twitter chat than our previous combination of spreadsheets and written summaries, which was very time intensive for the team "'- UKLC Volunteer

\section{CONCLUSION AND FURTHER RESEARCH}

Our analysis here contributes to open strategy literature in two ways. First, the background to this paper, including a summarized literature review of open strategy case examples, emphasizes the potential significance of external facilitators in open strategy, and acts as a motivation for exploring this theme further. Second, through analyzing two IT-driven open strategy initiatives, we identify four core roles being demonstrated by such external practitioners, these being structuring, promoting, moderating and analyzing. By explicitly highlighting the significance of external facilitators in open strategy, and outlining some of the roles they have, we consider that further research could build on this paper to investigate further dynamics between organizations and external facilitators in IT-driven open strategizing phenomena. An interesting aspect of this dynamic might be to explore the motivations of external facilitators in being involved in open strategy activity, or to identify different types of external facilitator involved in the open strategizing process.

This paper offers a series of initial findings that illuminates the roles played by external facilitators within open strategy initiatives. This extends the range of practitioners engaged in strategy. The roles of structuring, promoting, moderating and analyzing feed into new forms of praxis. We use this as a basis to argue for further investigation into the impact of external facilitators in shaping practice in open strategy.

\section{REFERENCES}

[1] Baptista, J., Wilson, A., Galliers, R. and Bynghal, S. (2015). An open strategy revolution? Emerging tensions and capabilities from using social media in organizational strategizing. In Showcase Symposium, Academy of Management (Vancouver, Canada, August 7-11, 2015).

[2] Brauner, R. and Kettner, N. (2014). Vienna Now or Never: Tourism Strategy 2020. Vienna Tourist Board. Available at: http://www.tourismstrategy2020.vienna.info. (Accessed 23/03/2016).

[3] Chesbrough, H. (2003). The Era of Open Innovation. MIT Sloan Review, (Apr. 2003), 36-37.

[4] Chesbrough, H. and Appleyard, M. M. (2007). Open Innovation and Strategy. California Management Review, 50(1), 57-76.

[5] Fitzgerald, B. (2014). Open strategy from Greenpeace Oceans meeting. Greenpeace.org.

[6] Friis, O. (2015). Openness in strategy: Social strategy practices and practitioner interaction. In The $31^{\text {st }}$ EGOS Colloquium (Athens, Greece, June 2-4, 2015).

[7] Hendry, J. and Seidl, D. (2003). The Structure and Significance of Strategic Episodes: Social Systems Theory and the Routine Practices of Strategic Change. Journal of Management Studies, 40 (1), 175-196.

[8] Howe, J. (2006). The Rise of Crowdsourcing. Wired Magazine, (Jun. 2006), 1-5.

[9] Jarzabkowski, P. (2005). Strategy as practice: An activity based approach. London: Sage.

[10] Jarzabkowski, P. (2010). An activity-theory approach to Strategy as Practice. In Golsorkhi, D., Rouleau, L., Seidl, D. and Vaara, E. Cambridge Handbook of Strategy as Practice. Cambridge: Cambridge University Press.

[11] Morton, J., Wilson, A. and Cooke, L. (2015). Collaboration and Knowledge Sharing in Open Strategy Initiatives. In iFutures 2015 (Sheffield, England, July 7, 2015).

[12] Morton, J., Wilson, A. and Cooke, L. (2016). Open Strategy Initiatives: Open, IT-enabled Episodes of Strategic Practice. In Twentieth Pacific Asia Conference on Information Systems (Chiayi, Taiwan, June 27-July 1, 2016).

[13] Newstead, B. and Lanzerotti, L. (2011). Can You OpenSource Your Strategy?. Harvard Business Review, (Oct 2010), 32.

[14] Pettigrew, A. (1985). The Awakening Giant: Continuity and Change at ICI. Oxford: Blackwell.

[15] Riehle, D., Ellenberger, J., Menahem, T., Mikhailovski, B., Natcheti, Y., Naveh, B. and Odenwald, T. (2009). Open Collaboration within Corporations Using Software Forges. IEEE Software, 26(2), 52-58.

[16] Stieger, D., Matzler, K., Chatterjee, S. and LadstaetterFussenegger, F. (2012). Democratizing Strategy: How Crowdsourcing Can Be Used For Strategy Dialogues. California Management Review, 54(4), 44-68.

[17] Webster, J. and Watson, R.T. (2002). Analyzing the Past to Prepare for the Future: Writing a Literature Review. MIS Quarterly, 26(2), xiii-xxiii.

[18] Whittington, R. (2006). Completing the Practice Turn in Strategy Research. Organization Studies, 27(5), 613-634.

[19] Whittington, R., Cailluet, L. and Yakis-Douglas, B. (2011). Opening Strategy: Evolution of a Precarious Profession. British Journal of Management. 22(3), 531-544. 